\title{
MERGEL, Thomas, Zwischen Klasse und Konfession. Katholisches Bürgertum im Rheinland 1794-1914
}

\section{Catherine Maurer}

\section{OpenEdition}

\section{Journals}

Édition électronique

URL : http://journals.openedition.org/ifha/1489

DOI : $10.4000 /$ ifha. 1489

ISSN : 2198-8943

Éditeur

IFRA - Institut franco-allemand (sciences historiques et sociales)

Référence électronique

Catherine Maurer, «MERGEL, Thomas, Zwischen Klasse und Konfession. Katholisches Bürgertum im Rheinland 1794-1974 », Revue de l'IFHA [En ligne], Date de recension, mis en ligne le 01 janvier 1998, consulté le 22 septembre 2020. URL : http://journals.openedition.org/ifha/1489 ; DOI : https://doi.org/ 10.4000/ifha.1489

Ce document a été généré automatiquement le 22 septembre 2020.

(C)IFHA 


\title{
MERGEL, Thomas, Zwischen Klasse und Konfession. Katholisches Bürgertum im Rheinland 1794-1914
}

\author{
Catherine Maurer
}

Il y a déjà une dizaine d'années, le Bulletin rendait compte de la vitalité de la recherche sur les bourgeoisies en Allemagne depuis le début des années 1970 (voir Bulletin, 17, décembre 1988, p.35-40). Les ouvrages présentés confirment cette vitalité. Les deux premiers font partie d'une série qui a publié les travaux sur l'histoire sociale du Bildungsbürgertum réalisés à l'initiative de Werner Conze par l'Arbeitskreis für moderne Sozialgeschichte et dont les tomes 1 et 4 sont parus en 1985 et 1989. Cette série reflète deux des premières grandes orientations de la recherche sur la bourgeoisie en Allemagne: l'importance accordée au XIXe s. et la tentative de définition de ce qui est généralement considéré comme une spécificité allemande, le Bildungsbürgertum (bourgeoisie de culture, bourgeoisie intellectuelle). Le tome 2 s'intéresse à la notion même de Bildung et à son contenu (voir la longue introduction de R.K.), le tome 3 aux modes de vie et à l'insertion dans la société des Bildungsbürger (voir les articles sur le rôle du théâtre ou des beaux-arts pour la bourgeoisie de culture ou la première esquisse de l'histoire d'une grande famille bourgeoise de Mannheim, les Bassermann, proposée par Lothar Gall et développée dans une publication ultérieure).

Le troisième ouvrage témoigne de l'intérêt que portent les Anglo-Saxons à l'histoire sociale de l'Allemagne, même si deux contributions (sur onze au total) sont dues à des historiennes allemandes, dont Ute Frevert. Le livre s'insère d'ailleurs dans une série de publications inaugurée en 1981 et portant sur l'histoire sociale de l'Allemagne, de l'histoire de la famille jusqu'à celle du monde ouvrier, en passant par les paysans et le rôle de la religion dans la société. The German Bourgeoisie permet à un public non germanophone de s'informer sur les tendances récentes de l'histoire de la bourgeoisie allemande, grâce à l'importante introduction rédigée par D.B., mais aussi à des études qui mêlent approche par groupes sociaux ou professionnels (Kommerzienräte prussiens, grande bourgeoisie de Hambourg ou avocats et médecins) et approche culturelle et politique (rôle du duel, relations entre bourgeoisie et libéralisme). Les 
contributions n'éludent pas les grandes questions qui se posent depuis l'origine aux historiens de la bourgeoisie allemande: problème de définition et de distinction, notamment entre la bourgeoisie de culture et la bourgeoisie économique, place de la bourgeoisie dans le débat sur le Sonderweg. Si elles portent essentiellement sur le XIXe s., deux d'entre elles abordent la période de la République de Weimar et la dernière contribution est consacrée aux relations entre classes moyennes et national-socialisme.

Dans la préface de The German Bourgeoisie, D.B. et R.J.E. disaient quelle était leur dette à l'égard des travaux menés depuis 1986 dans le cadre du Sonderforschungsbereich de l'université de Bielefeld consacré à l'histoire sociale de la bourgeoisie (voir Bulletin, 17). Les deux derniers ouvrages sont directement issus de ce programme de recherche particulièrement fécond. Le livre dirigé par K.T. et H.-U.W. est un recueil d'articles divisé en trois parties. La première explore de manière nouvelle les relations entre noblesse et bourgeoisie au XIXe s., à l'aide d'études de cas régionaux (Hesse-Cassel, Saxe) qui permettent de relativiser le modèle prussien (même si la Prusse n'est pas totalement absente), trop souvent accepté comme une norme valant pour l'ensemble de l'Allemagne, mais aussi de nuancer davantage encore la thèse désormais usée de la féodalisation de la bourgeoisie allemande. La seconde partie examine les indices culturels ou religieux qui permettraient d'identifier la ou les bourgeoisies, à partir de la mise en scène des entrées princières à Nuremberg à l'époque moderne, de la piété des femmes issues de la bourgeoisie ou du rôle de la religion et de l'éducation dans l'insertion sociale des pasteurs et de la bourgeoisie protestante dans le Grand-Duché de Bade de la fin du XIXe $s$. Enfin, la troisième et dernière partie n'est plus articulée autour d'un thème, mais autour d'une période, le XXe s. Elle permet de poser les jalons d'une histoire dont l'exploration est loin d'être terminée, à partir de différentes analyses de cas portant sur la manière dont les femmes de la bourgeoisie proches des premières organisations féminines envisageaient le travail social au début du siècle, sur la situation sociale des diplômés des écoles de commerce dans le premier tiers du siècle ou sur celle des diplômés de l'enseignement supérieur (Akademiker) lors des vingt premières années de la République fédérale. Au total, l'ouvrage offre une bonne approche des nouvelles »voies" empruntées par l'histoire de la bourgeoisie en Allemagne et montre comment un champ historiographique redécouvert relativement récemment a pu se renouveler rapidement.

À la différence de l'une des premières grandes publications issues des travaux du Sonderforschungsbereich de Bielefeld (Bürgertum im 19. Jahrhundert, ouvrage en 3 volumes dirigé par Jürgen Kocka: voir Bulletin, 17), le livre dirigé par Tenfelde et Wehler accorde déjà une attention plus grande au facteur religieux ou confessionnel, si important pour comprendre l'histoire de l'Allemagne. Ce facteur est au centre de la thèse de T.M., soutenue en 1993 devant l'université de Bielefeld. L'étude de T.M. est en effet consacrée à un groupe social défini partiellement par son appartenance confessionnelle: la bourgeoisie catholique rhénane, examinée sur plus d'un siècle, de 1794 à 1914. L'un des principaux objectifs de l'auteur était de réconcilier deux champs historiographiques trop radicalement séparés en Allemagne, l'histoire de la bourgeoisie et l'histoire du catholicisme, en recherchant dans quelle mesure identité catholique et identité bourgeoise, souvent associée au protestantisme en Allemagne, pouvaient se concilier chez les Bürger de Cologne et de Bonn, les deux villes-cible de l'analyse. Après une analyse fouillée alliant méthodes quantitatives (utilisation des listes électorales servant aux élections municipales et des listes des candidats au baccalauréat) et qualitatives (utilisation de fonds d'archives privées, de biographies et d'histoires 
familiales), T.M. a été ainsi en mesure de proposer une périodisation des liens entretenus entre identité catholique et identité bourgeoise dans la région considérée: jusqu'au milieu du XIXe s., ces deux identités n'entrent guère en conflit, l'idéal d'unité proclamé par la bourgeoisie rhénane se réalise aussi dans ce domaine; dans la période 1850-1870, les tensions se font plus vives, dans un contexte de développement de l'ultramontanisme d'un côté et de sécularisation des univers bourgeois de l'autre; enfin, la période inaugurée par le Kulturkampf permet à certains représentants de la bourgeoisie rhénane de reprendre un rôle directeur dans un milieu catholique qu'elle s'efforce de séculariser et surtout de »décléricaliser« (comme le montrent la création du Volksverein ou le soutien aux syndicats interconfessionnels), tandis qu'une partie importante du Bürgertum s'éloigne encore plus franchement de la religion et du milieu catholiques, ce qui résout inévitablement les tensions qui subsistaient entre les deux pôles de son identité. Mais l'étude de T.M. va au-delà de cette analyse associant histoire sociale et histoire religieuse: elle brosse plus largement le portrait d'une bourgeoisie catholique rhénane en élite partagée entre son attachement aux traditions héritées de la civilisation urbaine d'Ancien Régime et son entrée, tardive mais incontestable, dans l'univers de l'industrialisation, en élite consciente de sa valeur mais éprouvant, à la fin du siècle, le sentiment grandissant de sa perte d'influence dans le contexte de l'État national, enfin en élite soucieuse d'action sociale, mais souhaitant préserver l'organisation de la société qui lui a assuré ses privilèges. Au total, T.M., tout en ne reniant pas totalement les grands modèles théoriques, notamment le modèle wébérien, déterminants dans l'émergence de l'»école de Bielefeld« à laquelle il se rattache, propose une véritable étude de terrain, une histoire "par en-dessous « d'un certain type de bourgeoisie allemande, qui devrait donner des éléments de comparaison aux spécialistes français d'histoire sociale et d'histoire de la bourgeoisie. Tableaux statistiques, cartes, textes originaux et biographies collectives des principales familles étudiées, enfin index des noms de personnes et index thématique achèvent de faire de cet ouvrage un témoignage de la vigueur de la recherche chez les jeunes historiens allemands.

Catherine MAURER 